\title{
Smoking cessation and smokefree environments for tuberculosis patients in Indonesia-a cohort study
}

\author{
Tara Singh Bam ${ }^{1 *}$, Tjandra Yoga Aditama ${ }^{2}$, Chen-Yuan Chiang ${ }^{3,4}$, Rubaeah Rubaeah ${ }^{5}$ and Acep Suhaemi ${ }^{6}$
}

\begin{abstract}
Background: Research indicates that smoking substantially increases the risk of tuberculosis (TB), delay in diagnosis, failure of TB treatment and death from TB. Quitting smoking is one of the best ways to prevent unwanted outcomes. Exposure to secondhand smoke increases the risks of both TB infection and development of active TB disease among children and adults. TB patients who smoke in the home are also placing their families at a greater risk of TB infection. It is very important to keep homes smokefree. The present study assessed the implementation and effectiveness of an intervention that promotes smoking cessation and smokefree environments for TB patients.
\end{abstract}

Methods: All consecutive new sputum smear-positive TB patients (aged $\geq 15$ years old) diagnosed and registered in 17 health centres between 1 January 2011 and 31 December 2012 were enrolled. The ABC ( $=$ =ask, B=brief advice, $C=$ cessation support) intervention was offered for 5 to 10 minutes within DOTS services at each visit. Smoking status and smokefree environments at home were assessed at the first visit, each monthly follow up and at month six. Factors associated with quitting were analysed by univariable and multivariable analysis

Results: Of the 750 TB patients registered, 582 (77.6\%) were current smokers, 40 (5.3\%) were ex-smokers and 128 (17.1\%) were never smokers. Of the 582 current smokers, $66.8 \%$ had quit smoking at month six. A time from waking to first cigarette of $>30$ minutes, having a smokefree home and the display of "no smoking" signage at home at month six were significantly associated with quitting. Of the 750 TB patients, $86.1 \%$ had created a smokefree home at six month follow-up compared with $18.5 \%$ at baseline. All 80 health facilities were $100 \%$ tobacco-free at the end of 2012 compared with only 52 (65\%) when the intervention began in March 2011.

Conclusions: Brief advice of 5-10 minutes with minimal cessation support at every visit of TB patients resulted in high quit rates and higher awareness of adverse health effects of secondhand smoke exposure, which led patients to make their homes smokefree and health providers to make health care tobacco-free.

Keywords: Smoking, Cessation, Smokefree home, ABC-approach, Tuberculosis

\section{Background}

Tobacco smoking has rarely been mentioned among the challenges identified in tuberculosis (TB) control. The adverse association between smoking and TB is largely overlooked by clinicians treating ТB [1]. In a large epidemiological study, $50 \%$ of deaths from TB among Indian men was attributed to smoking [2]. A South Korean study demonstrated that current cigarette

\footnotetext{
* Correspondence: tsbam@theunion.org

${ }^{1}$ International Union Against Tuberculosis and Lung Disease, Robinson Road, Singapore

Full list of author information is available at the end of the article
}

smokers had a $40 \%$ increased risk of incident TB and were $55 \%$ more likely to die of TB as compared with nonsmokers [3]. World Health Organization (WHO) reported that more than $20 \%$ of global TB incidence may be attributable to smoking [4]. WHO and the International Union Against Tuberculosis and Lung Disease (The Union) published a Monograph on TB and Tobacco Control examining the associations between active and passive smoking and various TB outcomes including infection, occurrences of the disease, mortality, treatment outcomes and relapse after treatment [5].

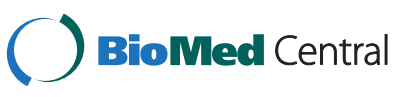

(c) 2015 Bam et al. This is an Open Access article distributed under the terms of the Creative Commons Attribution License (http://creativecommons.org/licenses/by/4.0), which permits unrestricted use, distribution, and reproduction in any medium, provided the original work is properly credited. The Creative Commons Public Domain Dedication waiver (http:// creativecommons.org/publicdomain/zero/1.0/) applies to the data made available in this article, unless otherwise stated. 
The Union's Lung Health Scientific Section established a working group on smoking cessation in TB patients in December 2009 at the World Lung Conference (WLC) in Cancun, Mexico to pilot a simple cost-effective approach that integrated TB and tobacco control measures within the existing health services. The working group consisted of governmental and non-governmental organisations from Bangladesh, Bhutan, Benin, Brazil, India, China, Indonesia, Nepal, South Africa, Pakistan, and Japan, Union members from different regions and countries, and staff of WHO [6]. This group's efforts led to the development of the $\mathrm{ABC}$ ( $\mathrm{A}=$ ask, $\mathrm{B}=$ brief advice, $\mathrm{C}=$ cessation support) approach outlined in The Union's guide Smoking Cessation and Smokefree Environments for Tuberculosis Patients published in 2010 [7]. The ABC approach was piloted within the regular Directly Observed Treatment Short Course (DOTS) system in Bangladesh, Benin, Brazil, China, India, Indonesia, Mongolia, and South Africa.

We assessed the implementation and effectiveness of the ABC smoking cessation approach for TB patients and the establishment of smokefree environments in health care facilities and the TB patients' homes in Indonesia. We report the findings of this assessment.

\section{Methods}

This was a cohort study assessing a field based intervention.

\section{Settings}

The burden of $\mathrm{TB}$ remains enormous in Indonesia. In 2012 , there were an estimated 460,000 (185 per 100,000$)$ incident cases of TB and 67,000 patients died from this disease. A total of 328,824 new and relapse TB cases were notified in 2012 [8]. Tobacco use is the leading cause of disease and premature death in Indonesia. WHO estimates that smoking kills 235,000 Indonesians annually and secondhand smoke takes another 25,000 lives. Smoking is largely unregulated and 61.4 million (36.1 \%) of adults currently use tobacco. Smoking prevalence has increased among males to $67.4 \%$ in 2011 from $53.4 \%$ in 1995 [9]. The intervention was piloted in Bogor city, which had a population of 800,000 in 2012 [10], a smoke-free policy that was established in 2010 and 25 government health centres providing primary health services.

\section{Study population}

Of the 25 health centres that provided DOTS services, 17 satisfied the criteria for piloting the intervention: 1) providing a written commitment to join the intervention, 2) having attended the initial training on smoking cessation and smoke-free environments in 2010, and 3) having registered at least 5 new sputum smear-positive TB cases in 2010. All consecutive new sputum smearpositive TB patients (aged $\geq 15$ years old) diagnosed and registered in the 17 health centres between 1 January 2011 and 31 December 2012 were enrolled in the intervention. They were recruited within 7 days of commencement of anti-TB treatment.

\section{Establishing $100 \%$ tobacco-free health care facilities}

We obtained written commitment from the Director of the City Health Office and the Head of each participating health centre to create tobacco-free services. Tobacco-free was defined as the absence of tobacco advertisement, promotion and sponsorship, the absence of any indoor or outdoor active smoking in the health facility, and the display of "No smoking" signage at the main entrance of the facility and removal of smoking-related accessories and items, such as ashtrays, smoking areas and cigarette butts. A total of 80 health facilities (including 17 DOTS health centres) participated in the tobacco-free initiative. An ABC orientation programme was conducted for all health staff at the health centres. Compliance of the 80 health facilities with their tobacco-free health care policy was assessed twice a year by the City Health Office and No Tobacco Community (civil society based in Bogor) using a standard checklist (Fig. 1). Assessment was usually conducted during the busiest hours.

\begin{tabular}{|lrl|}
\hline Inspector name:_ Health Centre: & \\
\hline Indicators & Yes $\quad$ No \\
\hline Absence of active smoking within health facility & \\
Absence of smoking area/room within health facility & \\
Absence of cigarette butt within health facility & \\
Absence of tobacco smoke smell in indoor places of health facility & \\
Absence of ashtray/ashbin within health facility & \\
Presence of No Smoking signage at main entrances of health facility & \\
Absence of any item related to tobacco advertising, promotion and sponsorship & \\
Absence of cigarette sale within health facility & \\
\hline
\end{tabular}

Fig. 1 Checklist used to monitor tobacco free health care facility in Bogor city 


\section{Establishing $A B C$ smoking cessation intervention}

$\mathbf{A}=$ Ask about smoking behaviour of $\mathrm{TB}$ patients via a face-to-face interview was conducted by health staff at each visit. At zero month of anti-TB treatment, they were asked: i) Do you smoke? ii) Have you smoked at all-even a puff-in the last three months? iii) Does anyone smoke inside your home? At all follow-up visits they were asked: i) Have you smoked at all-even a puff-in the last two weeks? ii) Does anyone smoke inside your home?

$\mathbf{B}=$ Brief advice which included personalised and general information was offered immediately at the DOTS clinic by the health staff at each visit. For smokers, personalised information consisted of 1) quitting smoking now you can recover properly from TB, and 2) as soon as you quit, your coughing and sputum will decrease. General advice for smokers and nonsmokers included 1) smoking and secondhand smoke is very harmful for your and your family's health; it causes diseases such as cancer, heart disease, chronic obstructive pulmonary disease, asthma, childhood pneumonia, and 2) to improve your and your family's health, please quit smoking (for smokers) and do not allow anyone to smoke inside the home.

C = Cessation support was provided along with brief advice at each visit. Patients were advised to i) tell family, friends, and colleagues that they are quitting; ii) remove smoking accessories from home and workplaces; and iii) make their home smokefree and avoid secondhand smoke, and they were given health education leaflets, pamphlets and "No smoking" signage to display at home.

\section{Creating smokefree environments at home}

Exposure to secondhand smoke was assessed and monitored as described above under $\mathrm{ABC}$ sections. TB patients were asked at zero month and at all follow up visits whether anyone was allowed to smoke inside the home, and whether "No smoking" signage was displayed at the main entrance of their home. Information obtained from the patient was verified with a family member that had accompanied the patient to the health centre. A telephone call was made to the patients' closest family member to confirm that the home environment was smokefree if the patient had attended the health centre unaccompanied by family members.

\section{Monitoring and evaluation}

A standard smoking cessation intervention card and register were adapted from The Union Guide 2010 (7). Information included in the smoking cessation intervention card were: age, sex, time from waking to first cigarette, as well as elements related to the intervention, such as frequency of $\mathrm{ABC}$ offered, smoking status, whether anyone smokes inside the home, confirmation of quit status by a family member and display of no smoking signs at home. The information was recorded from baseline to month six. ABC was offered for 5 to 10 minutes within the usual DOTS services. Information was updated on a monthly basis when patients were given $\mathrm{ABC}$. Information related to $\mathrm{TB}$ diagnosis and treatment was obtained from the TB register, which is available at each health centres. Information from the smoking cessation intervention card was transferred to the register on a quarterly basis. Staff from the health centres also made random visits to some patients' homes to see whether they had created smokefree environments at home. A standard checklist (Fig. 1) was used to monitor the tobacco-free status of the health care facilities. Quitting status and exposure to SHS were assessed by patients self-reporting during the period of anti-TB treatment and validated at month 6 through interviews (face-to-face or by telephone) with the family member that was closest to the patient. Telephone numbers were recorded in the smoking cessation intervention card and also available on the patient's TB treatment card.

\section{Definitions and outcome measures}

Current smoker was defined as 1) a patient at enrolment who has smoked in the last 3 months, even a puff, and 2) a patient at follow-up visit who has smoked in the last two weeks, even a puff, and has not made any attempt to quit (for at least 24 hours) since the last visit.

Ex-smoker was defined as a patient at enrolment who used to smoke but has not smoked in the last 3 months, not even a puff.

Never smoker was defined as a patient who has never smoked, not even a puff.

Smokefree was defined as zero evidence of smoking: absence of active smoking, the display of "no smoking" signage, and absence of smoking areas/rooms, ashtrays, cigarette butts and the smell of tobacco smoke.

Tobacco-free was defined as zero evidence of smoking and the absence of tobacco advertising, promotion, sponsorship and sales.

Quitter was defined as a smoker at baseline who has not smoked at all, even a puff, in the last 2 weeks at the follow-up visit(s).

Relapsed smoker was defined as a smoker at baseline who has tried to quit during the $\mathrm{ABC}$ intervention but has relapsed (has smoked in the last two weeks before the current visit but has made at least one quit attempt lasting at least 24 hours since the last visit).

Lost to follow-up was defined as a patient who did not attend the follow-up visit and whose status was unknown.

Died was defined as a patient who has died of any cause during anti-TB treatment. 


\section{Statistical analysis}

Data were analysed using SPSS version 13.0 (Statistical Package for the Social Sciences Inc. Chicago, IL, USA). Differences in frequency distributions were evaluated by the chi square test with $\mathrm{p}<0.05$ as statistically significant. Odds ratio (OR) and $95 \%$ confidence intervals $(\mathrm{CI})$ were estimated using univariable and multivariable binary logistic regression analysis.

\section{Ethical statement}

The Coordinating Committee of Scientific Activity of The Union, the Bogor City Government and City Health Office approved the $\mathrm{ABC}$ smoking cessation intervention and its implementation as part of routine TB services. Verbal consent was obtained from each patient and family member that participated in the intervention. Health workers obtained consent from patients to speak with their family members during the follow-up. This study assesses smoking cessation as part of routine services; all information was handled by the health care workers that were providing the routine care for the patients. No individual identifiers were provided to individuals outside the health service.

\section{Results}

\section{Tobacco-free health care}

Of the 80 health care facilities, 52 (65\%) were tobaccofree in March 2011, which increased to 80 (100\%) in December 2012 (Table 1). Smoking was not permitted in any buildings, grounds or carparks. Cigarettes were not sold, and tobacco advertising, promotion and sponsorship were not permitted on the premises.

\section{Smoking status and smokefree environments at home at baseline}

Of the 750 new smear-positive TB patients registered, 393 (54.4 \%) aged 15-34 years, 617 (82.3 \%) were male, $582(77.6 \%)$ were current smokers, 40 (5.3\%) were exsmokers and 128 (17.1\%) were never smokers. At baseline 139 (18.5 \%) had a smokefree home. Males (91.2 \%) were significantly more likely to be current smokers as compared to females $(14.3 \%)(\mathrm{P}<0.01)$; current smokers were less likely to have a smokefree home as compared to ex-smokers and never smokers $(\mathrm{p}=0.012)$. Only 12 $(1.6 \%)$ patients reported displaying "no smoking" signage at home at baseline (Table 2). Of the 582 current smokers, 199 (34.2 \%) usually had their first cigarette within 30 minutes after waking up.

\section{$A B C$ in creating smokefree environments at home}

The proportion of current smokers with a smokefree home increased from $16.5 \%$ at baseline to $85.9 \%$ at month six, and that of ex- and never smokers with smokefree homes from $32.5 \%$ to $92.5 \%$ and $23.4 \%$ to $85.2 \%$ respectively (Fig. 2). The proportion of patients displaying"No Smoking" Signage at home increased to $50.8 \%$ at month six from $1.6 \%$ at baseline (Table 3 ).

\section{$A B C$ for smoking cessation}

Table 4 presents the outcomes of the $\mathrm{ABC}$ smoking cessation intervention. The point prevalence of the quit rate was $41.1 \%$ at month 1 . It increased substantially to $66.8 \%$ at month six. Twenty-one self-reported quitters were identified as relapsed smokers after verification with a family member at month six. They were reclassified as relapsed smokers throughout the analysis.

Of the 389 quitters at month six, $82.3 \%$ had observed three months of continuous abstinence, $11.8 \%$ two months of continuous abstinence and $5.9 \%$ two weeks of continuous abstinence.

In multivariable logistic regression analysis (Table 5) three predictors remained independently associated with quitting: a time from waking to first cigarette of $>30 \mathrm{mi}-$ nutes, having a smokefree home and the display of "no smoking" signage at home at month six.

\section{Discussion}

The $A B C$ smoking cessation intervention was effective for: i) creating $100 \%$ tobacco-free health services, ii) promoting quitting smoking (66.8 \%) and iii) establishing

Table 1 Compliance with tobacco-free policy in 80 health facilities, Bogor City March 2011 -December 2012

\begin{tabular}{|c|c|c|c|c|}
\hline \multirow[t]{2}{*}{ Indicators } & March 2011 & October 2011 & March 2012 & December 2012 \\
\hline & Number (\%) & Number (\%) & Number (\%) & Number (\%) \\
\hline Presence of active smoking & $2(2.5)$ & $1(1.25)$ & $0(0)$ & $0(0)$ \\
\hline Presence of smoking area within facility & $1(1.3)$ & $0(0)$ & $0(0)$ & $0(0)$ \\
\hline Display of no smoking signage & $54(66.9)$ & $74(92)$ & $80(100)$ & $80(100)$ \\
\hline Presence of ashtrays & $0(0)$ & $1(1.25)$ & $0(0)$ & $0(0)$ \\
\hline Presence of cigarette butts & $22(27.5)$ & $0(0)$ & $0(0)$ & $0(0)$ \\
\hline Presence of any item related to tobacco advertising, promotion or sponsorship & $4(5.0)$ & $0(0)$ & $2(2.5)$ & $0(0)$ \\
\hline Presence of cigarette sale at health facility & $2(2.5)$ & $0(0)$ & $2(2.5)$ & $0(0)$ \\
\hline Overall compliance to tobacco-free health care policy & $52(65)$ & $73(91)$ & $78(98)$ & $80(100)$ \\
\hline
\end{tabular}


Table 2 Characteristics of 750 new sputum smear-positive TB patients, Bogor 2011-2012

\begin{tabular}{|c|c|c|c|c|c|}
\hline \multirow[t]{4}{*}{ Characteristics } & \multirow{3}{*}{$\begin{array}{l}\text { Total } \\
(\mathrm{N}=750)\end{array}$} & \multicolumn{3}{|l|}{ Smoking status } & \multirow{4}{*}{$P$ value } \\
\hline & & Current smokers & Ex-smokers & Never smokers & \\
\hline & & $(\mathrm{N}=582)$ & $(\mathrm{N}=40)$ & $(\mathrm{N}=128)$ & \\
\hline & n (\%) & n (\%) & n (\%) & n (\%) & \\
\hline Age years $^{a}$ & & & & & 0.053 \\
\hline $15-34$ & $393(54.4)$ & $302(51.9)$ & $17(42.5)$ & $74(57.8)$ & \\
\hline $35-54$ & $262(34.9)$ & $214(36.8)$ & $14(35.0)$ & $34(26.6)$ & \\
\hline$>54$ & $95(12.7)$ & $66(11.3)$ & $9(22.5)$ & $20(15.6)$ & \\
\hline Sex & & & & & $<0.01$ \\
\hline Male & $617(82.3)$ & $563(96.7)$ & $30(75.0)$ & $24(18.8)$ & \\
\hline Female & $133(17.7)$ & $19(3.3)$ & $10(25.0)$ & $104(81.2)$ & \\
\hline Smokefree home at baseline & & & & & 0.012 \\
\hline No & $611(81.5)$ & $486(83.5)$ & $27(67.5)$ & $98(76.6)$ & \\
\hline Yes & $139(18.5)$ & $96(16.5)$ & $13(32.5)$ & $30(23.4)$ & \\
\hline $\begin{array}{l}\text { Display of "No smoking" signage at home } \\
\text { at baseline }\end{array}$ & & & & & 0.172 \\
\hline Signage displayed & $12(1.6)$ & $12(2.1)$ & $0(0)$ & $0(0)$ & \\
\hline Signage not displayed & $738(98.4)$ & $570(97.9)$ & $40(100)$ & $28(100)$ & \\
\hline
\end{tabular}

smokefree environments at home (86.1\%). The high quit rates in our study are probably due to several factors, such as: i) the enabling environments in a health system that offers $100 \%$ tobacco-free health services; ii) routine screening for smoking and smokefree homes; iii) brief advice to quit smoking and to create smokefree homes; iv) cessation support with additional information on the danger of tobacco smoking and secondhand smoke, and v) regular reminders and encouragement of family members to quit smoking. A similar intervention piloted in Bangladesh and India also reported high quit rates of tobacco use (Bangladesh $82 \%$ and India $67.3 \%$ ). These studies identified brief advice through regular DOTS services as an effective intervention to promote quitting tobacco use [11, 12]. Guidelines for implementation of article 14 of the WHO Framework Convention on Tobacco Control recommend brief advice to stop using tobacco, usually taking only a few minutes, given to all tobacco users, usually during the course of a routine consultation or interaction [13].

Smoke-free environments encourage people to quit smoking and reduce the likelihood of exposure to secondhand smoke. Our study demonstrates that a smokefree environment at home is strongly associated with quitters, indicating that banning smoking inside the home might be a highly motivating act that convinces

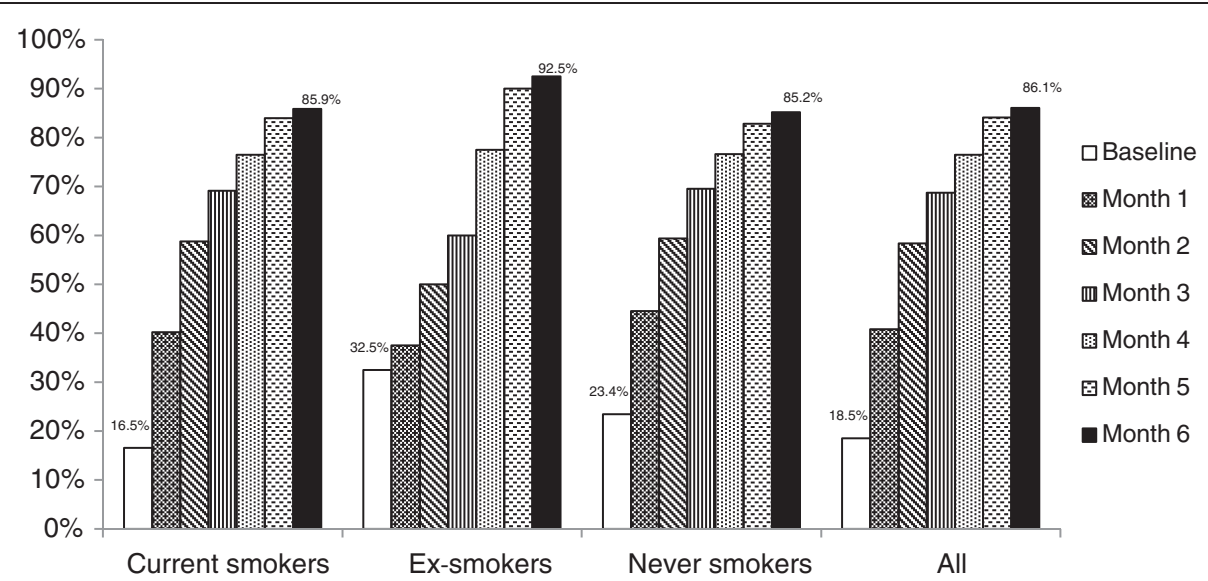

Fig. 2 Proportion of the patients with smokefree environments at home at baseline and during monthly follow up 
Table 3 Display of "No smoking" signage at home among 750 TB patients, at baseline and at six months

\begin{tabular}{|c|c|c|c|}
\hline \multirow[t]{3}{*}{ Smoking status } & \multirow{3}{*}{$\begin{array}{l}\text { Total } \\
\text { n }\end{array}$} & \multicolumn{2}{|c|}{ Display No smoking signage at home at baseline and after $A B C$} \\
\hline & & At baseline & At end of six months \\
\hline & & n (\%) & n (\%) \\
\hline Current smokers & 582 & $12(2.1)$ & $276(47.4)$ \\
\hline Ex-smokers & 40 & $0(0)$ & $20(50.0)$ \\
\hline Never smokers & 128 & $0(0)$ & $85(66.4)$ \\
\hline All & 750 & $12(1.6)$ & $381(50.8)$ \\
\hline
\end{tabular}

smokers to quit smoking and quitters to remain quitters. No smoking signage was used to conveying the message to family members and visitors to the home that smoking is prohibited. Therefore, our study suggests that smoking cessation counselling together with providing tobacco-free environments both at the health care facility and at home may produce a large public health impact.

Published evidence suggests that exposure to secondhand smoke increases the risk of developing a range of illnesses including lung cancer, heart disease, stroke, respiratory illness, sudden infant death syndrome (SIDS), ear infection, and severe asthma in children, pneumonia, and low birth weight [14]. We found $76.6 \%$ (98/ 128) of the never smokers with TB were exposed to secondhand smoke at home at baseline, indicating that scaling up the creation of smokefree environments at home may contribute to TB control because exposure to respirable pollutants due to the combustion of tobacco increases the risk of both TB infection and TB disease [15].

Most research identified that tobacco smoking increases the risk of developing $\mathrm{TB}$, delay in $\mathrm{TB}$ diagnosis, worse treatment outcomes and relapse $[5,16]$. Smokers who quit reduce both their risk of becoming infected with TB and their risk of dying from it. One study showed TB mortality dropping by almost two-thirds for quitters, compared to those who continued to smoke, and the risk for quitters almost returned to the level of those who had never smoked [17].Thus, prompt identification of smoking behaviour and smoking cessation are critical for improving TB treatment and reducing transmission of TB.

Our study has several strengths. Smokefree environments in all public places and work places have been established in Bogor city since 2010. The involvement of local health staff right from the beginning of the intervention has helped to sustain the smoking cessation care and tobacco-free environments in primary health services. All health centres were located in the community, so it was straightforward for health staff to conduct random inspections in patients' homes and to have informal interactions with patients to monitor progress. The study does, however, have some possible limitations. The outcomes of the intervention were largely evaluated on the basis of self-reporting. There might be a bias in the responses of the patients, in that they might have said what they thought the health worker would want to hear, thus overestimating the effect of the intervention. However, we have validated the status of the patients' smoking and of their smokefree home with a family member at month six. Issues of time constraints and high workload were raised at the initial training by the health staff before the intervention; however, health care workers reported neither high workloads nor time constraints during the review meeting at month two, five and six.

\section{Conclusions}

Our study has demonstrated the effectiveness of the 'ABC' smoking cessation intervention, which was delivered in just 5 to 10 minutes by health staff as a part of

Table 4 Point prevalence outcomes of ABC intervention among 582 current smokers with TB at baseline

\begin{tabular}{|c|c|c|c|c|c|c|}
\hline \multirow[t]{3}{*}{ Outcome } & \multicolumn{6}{|c|}{ Outcomes based on health staff asking patients about smoking status at monthly visits and on TB registers } \\
\hline & Month 1 & Month 2 & Month 3 & Month 4 & Month 5 & Month 6 \\
\hline & N (\%) & N (\%) & N (\%) & N (\%) & N (\%) & N (\%) \\
\hline Quitter & $239(41.1)$ & $329(56.5)$ & $366(62.9)$ & $388(66.7)$ & $406(69.8)$ & $389(66.8)$ \\
\hline Relapsed smoker & $37(6.4)$ & $56(9.6)$ & $74(12.7)$ & 70 (12.0) & $54(9.3)$ & $62(10.7)$ \\
\hline Died & $2(0.3)$ & $5(0.9)$ & $7(1.2)$ & $11(1.9)$ & $15(2.6)$ & $15(2.6)$ \\
\hline Lost to follow up & $17(2.9)$ & $37(6.4)$ & $39(6.7)$ & $51(8.8)$ & $56(9.6)$ & $71(12.2)$ \\
\hline Current smoker & $287(49.3)$ & 155 (26.6) & $96(16.5)$ & $62(10.7)$ & $51(8.8)$ & $45(7.7)$ \\
\hline Total & $582(100)$ & $582(100)$ & $582(100)$ & $582(100)$ & $582(100)$ & $582(100)$ \\
\hline
\end{tabular}


Table 5 Multiple logistic regression analysis of factors associated with quitters

\begin{tabular}{|c|c|c|c|c|}
\hline \multirow[t]{2}{*}{ Characteristics } & \multicolumn{4}{|c|}{ Smoking status at month 6 after $A B C$ intervention } \\
\hline & $\begin{array}{l}\text { Patients } \\
(\mathrm{N}=582)\end{array}$ & $\begin{array}{l}\text { Quitters } \\
\mathrm{n}(\%)\end{array}$ & $\begin{array}{l}\text { Odds ratio (OR) } 95 \% \\
\text { Confidence interval }(\mathrm{Cl})\end{array}$ & $\begin{array}{l}\text { Adjusted OR } \\
95 \% \mathrm{Cl}\end{array}$ \\
\hline \multicolumn{5}{|l|}{ Age, years } \\
\hline 15-34 (reference) & 302 & $204(67.5)$ & 1.00 & 1.00 \\
\hline $35-54$ & 214 & $143(66.8)$ & $1.19(0.68-2.07)$ & $1.07(0.54-2.10)$ \\
\hline$>54$ & 66 & $42(63.6)$ & $1.15(0.64-2.04)$ & $0.98(0.49-1.97)$ \\
\hline \multicolumn{5}{|l|}{ Sex } \\
\hline Female (reference) & 19 & $12(63.2)$ & 1.00 & 1.00 \\
\hline Male & 563 & $377(67.0)$ & $1.18(0.46-3.05)$ & $1.48(0.48-4.57)$ \\
\hline \multicolumn{5}{|c|}{ Time from waking to first cigarette } \\
\hline$\leq 30$ minutes (reference) & 199 & $96(48.2)$ & 1.00 & 1.00 \\
\hline$>30$ minutes & 383 & $293(76.5)$ & $3.49(2.43-5.03)$ & $3.14(2.05-4.81)$ \\
\hline \multicolumn{5}{|c|}{ Smokefree environments at home after $\mathrm{ABC}$ intervention } \\
\hline No (reference) & 82 & $20(24.4)$ & 1.00 & 1.00 \\
\hline Yes & 500 & $369(73.8)$ & $8.73(5.08-15.01)$ & $3.23(1.79-5.82)$ \\
\hline \multicolumn{5}{|c|}{ Display of "no smoking" signage at home after $A B C$ intervention } \\
\hline No (reference) & 306 & $141(46.1)$ & 1.00 & 1.00 \\
\hline Yes & 276 & $248(89.9)$ & $10.37(6.60-16.27)$ & $7.75(4.78-12.57)$ \\
\hline
\end{tabular}

existing DOTS services. The intervention resulted in high quit rates and higher awareness of the adverse health effects of secondhand smoke, which led patients to make smoke-free homes and health providers to make tobacco-free health care. The study also proved that $\mathrm{ABC}$ is feasible in DOTS services and primary health care in Indonesia. We believe that $\mathrm{ABC}$ can and should be generalised to other services and levels of care in Indonesia. It can be integrated into general primary health care services to enhance the impact of public health programmes, through implementing effective measures of tobacco control such as smoke-free environments, banning tobacco advertising, promotion and sponsorship and offering help to quit tobacco use.

\section{What this paper adds to}

Ingredients to produce high quit rates are:

- Creating smokefree environments in health services

- Offering Ask, Brief advice with minimal Cessation support by health workers at each visit

- Engaging family members to support patients to quit smoking

- Providing additional information on the dangers of smoking and secondhand smoke

- Encouraging patients and family members to create smoke-free environments at home

- Providing No smoking signage to display at home
- Monitoring the status of the intervention through face-to-face interaction with patients and family members

\section{Competing interests}

The authors declare that they have no competing interests.

\section{Authors' contributions}

TSB participated in the design and implementation of the study, performed the data analysis and drafted the manuscript. TYA participated in the design and implementation of the study. CYC participated in the design of the study, helped data analysis and drafted the manuscript. RR participated in the monitoring for the study and helped coordination. AS helped with the field work and coordination. All authors read and approved the final manuscript.

\section{Acknowledgements}

The authors thank the Bogor City Government, Bogor City Health Office; all participating health centres (PUSKESMAS), No Tobacco Community and The Union Working Group on Smoking Cessation for Tuberculosis Patients (2009-2013). The authors also thank and acknowledge the technical guidance of Prof. Donald A Enarson, Dr. Karen Bissell and Dr. Ehsan Latif. The authors also thank the Bloomberg Initiative to Reduce Tobacco Use for supporting smokefree Bogor City.

\section{Author details}

${ }^{1}$ International Union Against Tuberculosis and Lung Disease, Robinson Road, Singapore. ${ }^{2}$ Directorate General Disease Control and Environmental Health, Ministry of Health, Jakarta, Indonesia. ${ }^{3}$ International Union Against Tuberculosis and Lung Disease, Paris, France. ${ }^{4}$ Division of Pulmonary Medicine, Department of Internal Medicine, Wan Fang Hospital, Taipe Medical University, Taipei, Taiwan. ${ }^{5}$ Bogor City Health Office, Bogor, Indonesia. ${ }^{6} \mathrm{No}$ Tobacco Community, Bogor, Indonesia.

Received: 27 January 2015 Accepted: 25 June 2015

Published online: 02 July 2015 


\section{References}

1. Maurya V, Vijayan K, Shah A. Smoking and tuberculosis: an association overlooked. Int J Tuberc Lung Dis. 2002;6(11):942-51.

2. Gajalakshmi V, Peto R, Kanaka TS, Jha P. Smoking and mortality from tuberculosis and other diseases in India: retrospective study of 43000 adults male deaths and 35000 controls. Lancet. 2003:362(9383):507-15.

3. Sun Ha J, Jonathan EG, Jaeseong J, II Su P, Heechoul O, Jonathan MS. Smoking and risk of tuberculosis incidence, mortality and recurrence in South Korean Men and Women. Am J Epidemiol. 2009;170:1478-85.

4. World Health Organization: Tuberculosis and Tobacco. World Health Organization, Geneva. http://www.who.int/tobacco/publications/ health_effects/factsheet_tub_tob.pdf?ua=1. Accessed 31 December 2014.

5. World Health Organization. A WHO/The Union Monograph on TB and Tobacco Control: joining efforts to control two related global epidemics. Geneva: World Health Organization; 2007.

6. Bissell K, Fraser T, Bam TS. World No Tobacco Day: from an international treaty to country level action. Int J Tuberc Lung Dis. 2011;15(5):570.

7. Bissell K, Fraser T, Chiang C-Y, Enarson DA: Smoking cessation and smokefree environments for tuberculosis patients. Paris, France: International Union Against Tuberculosis and Lung Disease, 2010. http://www.theunion.org/what-we-do/ publications/technical/smoking-cessation-and-smokefree-environmentsfor-tuberculosis-patients. Accessed 2 January 2015.

8. World Health Organization: Global Tuberculosis Report 2013. WHO, Geneva. www.who.int/iris/bitstream/10665/91355/1/9789241564656_eng.pdf. Accessed 5 December 2014.

9. World Health Organization Regional Office for South East Asia: Global Adult Tobacco Survey: Indonesia Report 2011. New Delhi, India: WHO, 2012. http://www.who.int/tobacco/surveillance/survey/gats/indonesia_report.pdf. Accessed 5 December 2014.

10. United Nations, Department of Economic and Social Welfare: World Population Prospects: The 2012 Revision http://worldpopulationreview.com/ countries/indonesia-population/major-cities-in-indonesia/. Accessed 10 December 2014

11. Siddiquea BN, Islam MA, Bam TS, Satyanarayana S, Enarson DA, Reid AJ, et al. High quit rate among smokers with tuberculosis in a modified smoking cessation programme in Dhaka, Bangladesh. PHA. 2013;3(3):243-6.

12. Kaur J, Sachdeva KS, Modi B, Jain DC, Chauhan LS, Dave P, et al. Promoting tobacco cessation by integrating 'brief advice' in tuberculosis control programme. WHO South-East Asia J Public Health. 2013;2:28-33.

13. World Health Organization: Guidelines for Implementation of article 14 of the WHO Framework Convention on Tobacco Control. Geneva: WHO 2010 http://www.who.int/fctc/guidelines/adopted/article_14/en/. Accessed 10 December 2014

14. U.S. Department of Health and Human Services. The Health Consequences of Involuntary Exposure to Tobacco Smoke: A Report of the Surgeon General. Atlanta, Georgia: U.S. Department of Health and Human Services, Centers for Disease Control and Prevention, Coordinating Center for Health Promotion, National Center for Chronic Disease Prevention and Health Promotion, Office on Smoking and Health. 2006.

15. Lin HH, Ezzati M, Murray M. Tobacco Smoke, Indoor Air Pollution and Tuberculosis: A Systematic Review and Meta-Analysis. PLoS Med. 2007;4(1), e20. doi:10.1371/journal.pmed.0040020.

16. Bam TS, Enarson DA, Hinderaker SG, Bam DS: Longer delay in accessing treatment among current smokers with new sputum smear-positive tuberculosis in Nepal. Int J Tuberc Lung Dis 2012;16(6):822-7. http://www.ncbi.nlm.nih.gov/ pubmed/22507563. Accessed 3 November 2014.

17. Wen C-P. The reduction of tuberculosis risks by smoking cessation. BMC Infect Dis. 2010;10:156.

\section{Submit your next manuscript to BioMed Central and take full advantage of:}

- Convenient online submission

- Thorough peer review

- No space constraints or color figure charges

- Immediate publication on acceptance

- Inclusion in PubMed, CAS, Scopus and Google Scholar

- Research which is freely available for redistribution

Submit your manuscript at www.biomedcentral.com/submit 